\title{
Epidemiology of intramammary infections with Staphylococcus aureus and mastitis streptococci in a dairy cattle herd with a history of recurrent clinical mastitis
}

\author{
H. Vlkova ${ }^{1}$, V. Babak ${ }^{1}$, I. Vrtkova ${ }^{2}$, D. Cervinkova ${ }^{1}$, \\ D. Marosevic ${ }^{1}$, M. Moravkova ${ }^{1}$, Z. Jaglic ${ }^{1}$ \\ ${ }^{1}$ Department Food and Feed Safety, Veterinary Research Institute, \\ Hudcova 70, 621 00, Brno, Czech Republic \\ ${ }^{2}$ Laboratory of Agrogenomics, Mendel University in Brno, \\ Zemedelska 1/1665, 61300 Brno, Czech Republic
}

\begin{abstract}
The aim of the present work was to examine a dairy herd with an anamnesis of recurrent clinical mastitis and decreased milk production. A total of 239 individual cow milk samples originating from asymptomatic cows were collected at four-month intervals and examined mainly for the presence of Staphylococcus aureus and mastitis streptococci using standard cultivation methods. In total, 29.7\% and $9.2 \%$ samples were positive for $S$. aureus and mastitis streptococci, respectively. Unlike for mastitis streptococci, the prevalence of animals positive for $S$. aureus had an increasing trend $(\mathrm{p}<0.05$; Chi-squared test for trend) with rising parity. Despite in vitro susceptibility of $S$. aureus to potentiated penicillins and cephalosporins, the persistence of $S$. aureus was observed in cows undergoing intramammary treatment with amoxicillin/clavulanic acid (a potentiated penicillin antibiotic). All isolates of $S$. aureus were biofilm-positive and had the same macrorestriction pattern. Furthermore, no dependence was observed between the occurrence of $S$. aureus in milk and previous cases of clinical mastitis, reproductive and periparturient disorders and administration of antibiotics. In contrast to $S$. aureus, the occurrence of mastitis streptococci in milk was linked with previous cases of clinical mastitis and intramammary administration of antibiotics.
\end{abstract}

Key words: mastitis, bovine, resistance, Staphylococcus aureus, mastitis streptococci 


\section{Introduction}

Despite considerable research efforts towards the development of effective prevention and treatment strategies, mastitis continues to be a significant issue in bovine veterinary medicine (Awale et al. 2012). Moreover, bacterial agents that are involved in bovine mastitis may represent a health risk for the human population via the food chain (Kadariya et al. 2014).

Among mastitis pathogens, Staphylococcus aureus and so-called mastitis streptococci (Streptococcus uberis, $S$. dysgalactiae and $S$. agalactiae) are considered as the significant causal agents (Awale et al. 2012). Clinical cases in lactating cows should be treated with an appropriate intramammary antibiotic. Nevertheless, frequent use of antibiotics can lead to the development of resistant bacterial populations and persistent mastitis infection in the herd (Osteras et al. 1999). Cows with subclinical mastitis do not show any clinical signs of infection but can be diagnosed by somatic cell count (SCC) and by detection of the presence of pathogenic microorganisms (Ferreira et al. 2012). Subclinical mastitis is 15 to 40 times more prevalent than the clinical form of mastitis and therefore it is considered to be of greater significance than the clinical form (Seegers et al. 2003).

The aim of the present work was to examine a dairy herd with an anamnesis of recurrent clinical mastitis and decreased milk production. The prevalence of $S$. aureus and mastitis streptococci in milk from subclinical cows was studied with respect to parameters such as parity, somatic cell count in milk, total bacterial count (TBC) in milk, health status of the herd (different reproductive and periparturient disorders (RPD; ovarian dysfunctions, metritis, retained placenta and milk fever), occurrence of clinical mastitis and administration of antibiotics. The study was an attempt to answer the question of whether the persistence of $S$. aureus and mastitis streptococci was due to treatment failure or due to reinfection with different strains of $S$. aureus. Therefore $S$. aureus and staphylococci isolates were further characterized with respect to their antimicrobial resistance profile. S. aureus isolates were also analyzed for their clonality and ability to form biofilm. In addition, the prevalence of other potential pathogens (coagulase-negative staphylococci (CNS), other streptococci, Enterococcus faecalis/faecium (EFS) and other enterococci) was examined.

\section{Materials and Methods}

\section{Herd description}

The study was conducted in a closed breeding herd of Fleckvieh cattle with an anamnesis of recurrent clini- cal mastitis treated intramammarily with amoxicillin/ clavulanic acid. An average number of dairy cows was about 400 animals over a period of one year. The animals were housed in a loose housing barn, cubicle system and manure corridors with grade, and milked twice daily using an auto-tandem milking parlor. The average milk yield ranged from 6000 to $8000 \mathrm{~kg}$ per year.

\section{Sampling and microbial examination}

A total of 239 individual cow milk samples were collected during the period of one year at four-month intervals (approximately 60 samples per collection). Only cows showing no clinical signs of mastitis were sampled. Whenever possible, the same cows were sampled at each sample collection. From a total of 91 sampled cows, 13 cows were sampled four times, 40 cows three times, 29 cows twice and 9 cows were sampled once.

Sampling of milk and subsequent processing of the samples were done according to the EN ISO 6887-5 standard. S. aureus and coagulase-negative staphylococci were detected and identified according to EN ISO 6888-1 standard. Streptococci (S. uberis, $S$. dysgalactiae and $S$. agalactiae) and enterococci were cultivated on Edwards Medium Modified agar (Oxoid, Basingstoke, UK) and identified as described previously (Cervinkova et al. 2013). Isolates of $S$. aureus were additionally confirmed using PCR (Martineau et al. 1998).

\section{Determination of SCC and TBC in milk}

Determination of SCC using the fluoro-opto-electronic method was carried out on the Somacount 500 (Bentley Instruments, USA) according to the EN ISO 13366-2:2007 standard. Somatic cell count numbers above 150000 (Kvapilik 2015) were used as the threshold for likely subclinical infection of individual cow. Determination of TBC by automated enumeration of bacterial cells was carried out on the BactoCount IBC (Bentley Instruments, USA) according to CSN 57 0539:1999.

\section{Antimicrobial susceptibility, biofilm formation and molecular typing of isolates}

Minimum inhibitory concentrations of tested antibiotics (ampicillin, ampicillin/sulbactam, cloxacillin, gentamicin, cotrimoxazol, tetracycline, clindamycin, neomycin, tylosin, cephalothin, cefotaxime and norfloxacin; Sigma, St. Louis, MO, USA) were determined for all the isolates of $\mathrm{S}$. aureus and mastitis streptococci 
using the broth microdilution method according to the standard of the Clinical and Laboratory Standards Institute (CLSI document VET01-A4, 2013). For the interpretation of antimicrobial susceptibility, CLSI guidelines VET01-S2 (2013) and M100-S20 (2010) were preferentially used. When interpretation criteria were not available in the CLSI guidelines, the recommendations of the Antibiogram Committee of the French Society for Microbiology were used (CA-SFM, 2014). S. aureus isolates were further screened for methicillin resistance by testing their susceptibility to a cefoxitin $30 \mu \mathrm{g}$ disc (Oxoid, Basingstoke, UK), in accord with a CLSI document VET01-S2 (2013). S. aureus isolates were tested for the production of $\beta$-lactamases according to CLSI guidelines VET01-S2 (2013), using a nitrocefin-based test (ERBA-LACHEMA, Czech Republic). When appropriate, $S$. aureus ATCC 25923, ATCC 43300 and ATCC 29213 served as reference strains for quality control purposes.

The ability to form biofilm was tested in $S$. aureus isolates using polystyrene microtitration plates (Stepanovic et al. 2007). Using PCR, the isolates were also examined for the presence of biofilm genes (icaAB and bap) as described previously (Cervinkova et al. 2013). To confirm the persistence and clonality of $S$. aureus in the herd during the one year period, the isolates were subjected to pulsed field gel electrophoresis (PFGE) analysis as previously described (Jaglic et al. 2010).

\section{Statistical analysis}

Statistical analysis was performed using the statistical software GraphPad Prism, version 5.04 (GraphPad Software, Inc., San Diego, CA, USA). P-values lower than 0.05 were considered statistically significant. Prevalence of mastitis pathogens was evaluated using Fisher's exact test. In cases of a significantly different prevalence, odds ratio (OR) was calculated. The Chi-squared test for trend was used to assess the effect of parity and repeated sampling on the prevalence of the pathogens.

\section{Results}

\section{Occurrence of Staphylococcus aureus and other pathogens}

Out of 239 milk samples, $71(29.7 \%)$ and $22(9.2 \%)$ samples were positive for $S$. aureus and mastitis streptococci, respectively. The prevalence of $S$. aureus varied from 23.3 to $39.0 \%$ and for mastitis streptococci from $1.7 \%$ to $15.0 \%$ during four sample collections within the study. In addition to primary mastitis pathogens, CNS, other streptococci, EFS and other enterococci were detected in $123(51.5 \%), 42$ (17.6\%), 34 (14.2\%) and 38 (15.9\%) samples, respectively.

The prevalence of $S$. aureus and mastitis streptococci with respect to the total number of samplings of individual animals is summarized in Table 1. Unlike for mastitis streptococci, the probability of a positive finding for $S$. aureus increased with the increasing number of samplings ( $\mathrm{p}<0.05$; Chi-squared test for trend). Analysis of the prevalence of $S$. aureus and mastitis streptococci in milk with respect to parity revealed that cows that were in a higher parity were more frequently positive for S. aureus $(\mathrm{p}<0.01$; Chi-squared test for trend; Table 2$)$. This implies that the risk of $S$. aureus mastitis may increase with increasing parity number. However, this phenomenon was not statistically significant with mastitis streptococci ( $p>0.05$; Chi-squared test for trend; Table 2).

The relationship between the prevalence of Staphylococcus aureus and mastitis streptococci in milk, and occurrence of clinical mastitis, reproductive and periparturient disorders and administration of antibiotics is described in Table 4. According to these results, there was only seen statistical significance for clinical mastitis and intramammary administration of antibiotics and mastitis streptococci $(\mathrm{p}<0.05$; Fisher's exact test).

The relationship between the prevalence of studied pathogens and SCC or TBC values of milk is described in Table 3. Statistically significant increase in prevalence of $S$. aureus and mastitis streptococci was associated with the higher SCC numbers $(>150000 ; \mathrm{p}<0.05$ at least; Fisher's exact test; Table 3). This relationship was not confirmed for other potential mastitis pathogens (Table 3). Statistically significant increase in prevalence of $S$. aureus, mastitis streptococci, other streptococci and EFS was also correlated with higher TBC numbers $(>100$ 000; $\mathrm{p}<0.05$; Fisher's exact test; Table 3), except other enterococci ( $p>0.05$; Fisher's exact test; Table 3$)$.

\section{Antimicrobial susceptibility}

All 71 isolates of $S$. aureus were resistant to ampicillin and produced $\beta$-lactamases. Neither methicillin-resistance nor resistance to other antimicrobials was observed in $S$. aureus isolates. Among mastitis streptococci, resistance to ampicillin and ampicillin/sulbactam was detected in all isolates whereas resistance to tetracycline was found in $14(63.6 \%)$ isolates. Resistance to other antimicrobials was observed less frequently: four isolates were resistant to norfloxacin, two to clindamycin and one isolate was resistant to either cotrimoxazol or tylosin. 
Table 1. Prevalence of cows positive for Staphylococcus aureus and mastitis streptococci with respect to the total number of samplings of individual animals.

\begin{tabular}{|c|c|c|c|c|c|c|c|c|c|c|}
\hline \multirow{3}{*}{$\begin{array}{l}\text { Total number } \\
\text { of samplings** }\end{array}$} & \multicolumn{5}{|c|}{ Staphylococcus aureus $(n=71)$} & \multicolumn{5}{|c|}{ Mastitis streptococci $(n=22)^{*}$} \\
\hline & \multicolumn{5}{|c|}{ positive cows } & \multicolumn{5}{|c|}{ positive cows } \\
\hline & once & twice & $\begin{array}{l}\text { three } \\
\text { times }\end{array}$ & $\begin{array}{l}\text { four } \\
\text { times }\end{array}$ & $\begin{array}{l}\text { total } \\
(\%)\end{array}$ & once & twice & $\begin{array}{l}\text { three } \\
\text { times }\end{array}$ & $\begin{array}{l}\text { four } \\
\text { times }\end{array}$ & $\begin{array}{l}\text { total } \\
(\%)\end{array}$ \\
\hline Four times $(n=13)$ & 4 & 1 & 1 & 2 & $8(61.5)$ & 3 & 2 & 0 & 0 & $5(38.5)$ \\
\hline Three times $(n=40)$ & 11 & 5 & 5 & NA & $21(52.5)$ & 9 & 0 & 0 & NA & $9(22.5)$ \\
\hline Twice $(n=29)$ & 7 & 5 & NA & NA & $12(41.4)$ & 1 & 1 & NA & NA & $2(6.9)$ \\
\hline Once $(n=9)$ & 1 & NA & NA & NA & $(11.1)$ & 3 & NA & NA & NA & $3(33.3)$ \\
\hline
\end{tabular}

* Streptococcus uberis $(n=13)$, Streptococcus dysgalactiae $(n=8)$ and Streptococcus agalactiae $(n=1)$; NA = not applicable;

** number of cows are indicated in parenthesis; $n$ - number of samples

Table 2. Prevalence of samples positive for Staphylococcus aureus and mastitis streptococci with respect to the number of parity.

\begin{tabular}{cccccc}
\hline \multirow{2}{*}{ Parity } & \multirow{2}{*}{ Number of samples } & \multicolumn{2}{c}{ Staphylococcus aureus } & \multicolumn{2}{c}{ Mastitis streptococci } \\
\cline { 2 - 6 } & & $n$ & $\%$ & $n$ & 4 \\
\hline $1-2$ & 69 & 15 & 21.7 & 7 & 5.8 \\
\hline $3-4$ & 87 & 20 & 23.0 & 8 & 13.3 \\
\hline$\geq 5$ & 60 & 29 & 48.3 & 19 & 8.8 \\
\hline Total & 216 & 64 & 29.6 & 7 & 7 \\
\hline
\end{tabular}

$n$ - number of samples

Table 3. Prevalence of mastitis pathogens in milk samples with indicated values of somatic cell count and total bacterial count.

\begin{tabular}{|c|c|c|c|c|c|c|c|c|c|c|c|c|c|}
\hline \multirow{2}{*}{$\begin{array}{l}\text { Indicated } \\
\text { values }\end{array}$} & \multirow{2}{*}{$\begin{array}{c}\text { No of } \\
\text { samples }\end{array}$} & \multicolumn{2}{|c|}{$\begin{array}{c}\text { Staphylococcus } \\
\text { aureus }\end{array}$} & \multicolumn{2}{|c|}{$\begin{array}{c}\text { Mastitis } \\
\text { streptococci }\end{array}$} & \multicolumn{2}{|c|}{$\begin{array}{c}\text { Other } \\
\text { streptococci }\end{array}$} & \multicolumn{2}{|c|}{$\mathrm{CNS}$} & \multicolumn{2}{|c|}{$\begin{array}{c}\text { Enterococcus } \\
\text { faecalis/faecium }\end{array}$} & \multicolumn{2}{|c|}{$\begin{array}{c}\text { Other } \\
\text { enterococci }\end{array}$} \\
\hline & & $n$ & $\%$ & $n$ & $\%$ & $n$ & $\%$ & $n$ & $\%$ & $n$ & $\%$ & $n$ & $\%$ \\
\hline $\mathrm{SCC} \leq 150000$ & 90 & 17 & 18.9 & 4 & 4.4 & 19 & 21.1 & 49 & 54.4 & 8 & 8.9 & 16 & 17.8 \\
\hline \multirow[t]{2}{*}{$\mathrm{SCC}>150000$} & 86 & 35 & 40.7 & 14 & 16.3 & 9 & 10.5 & 43 & 50.0 & 11 & 12.8 & 7 & 8.1 \\
\hline & & \multicolumn{2}{|c|}{$\mathrm{p}<0.01 \mathrm{OR}=2.9$} & \multicolumn{2}{|c|}{$\mathrm{p}<0.05 \mathrm{OR}=4.2$} & \multicolumn{2}{|c|}{ n.s. } & \multicolumn{2}{|c|}{ n.s. } & \multicolumn{2}{|c|}{ n.s. } & \multicolumn{2}{|c|}{ n.s. } \\
\hline $\mathrm{TBC} \leq 100000$ & 109 & 20 & 18.3 & 6 & 5.5 & 13 & 11.9 & 71 & 65.1 & 7 & 6.4 & 13 & 11.9 \\
\hline \multirow[t]{2}{*}{$\mathrm{TBC}>100000$} & 70 & 33 & 47.1 & 12 & 17.1 & 17 & 24.3 & 21 & 30.0 & 12 & 17.1 & 11 & 15.7 \\
\hline & & \multicolumn{2}{|c|}{$\mathrm{p}<0.01 \mathrm{OR}=4.0$} & \multicolumn{2}{|c|}{$\mathrm{p}<0.05 \mathrm{OR}=3.6$} & \multicolumn{2}{|c|}{$\mathrm{p}<0.05 \mathrm{OR}=2.4$} & \multicolumn{2}{|c|}{$\mathrm{p}<0.01 \mathrm{OR}=0.2$} & \multicolumn{2}{|c|}{$\mathrm{p}<0.05 \mathrm{OR}=3.0$} & \multicolumn{2}{|c|}{ n.s. } \\
\hline
\end{tabular}

No - number, CNS - coagulase negative staphylococci; $p$ - significance; OR - odds ratio; n.s. - non significant; SCC - somatic cell count; TBC - total bacterial count

Table 4. Relationship between the prevalence of Staphylococcus aureus and mastitis streptococci in milk, occurrence of clinical mastitis $(\mathrm{CM})$, reproductive and periparturient disorders and administration of antibiotics.

\begin{tabular}{|c|c|c|c|c|}
\hline & \multirow[b]{2}{*}{$\mathrm{CM}$} & \multirow{2}{*}{ RPD } & \multicolumn{2}{|c|}{ ATB* $^{*}$} \\
\hline & & & total & intramammary \\
\hline \multicolumn{5}{|l|}{ Staphylococcus aureus } \\
\hline positive samples $(\mathrm{n}=71)$ & $5(7.0 \%)$ & $7(9.9 \%)$ & $15(21.1 \%)$ & $8(11.3 \%)$ \\
\hline negative samples $(\mathrm{n}=168)$ & $12(7.1 \%)$ & $17(10.1 \%)$ & $26(15.5 \%)$ & $20(11.9 \%)$ \\
\hline significance & n.s. & n.s. & n.s. & n.s. \\
\hline odds ratio & - & - & - & - \\
\hline \multicolumn{5}{|l|}{ Mastitis streptococci** } \\
\hline positive samples $(\mathrm{n}=22)$ & $5(22.7 \%)$ & $3(13.6 \%)$ & $7(31.8 \%)$ & $6(27.3 \%)$ \\
\hline negative samples $(\mathrm{n}=217)$ & $12(5.5 \%)$ & $21(9.7 \%)$ & $34(15.7 \%)$ & $22(10.1 \%)$ \\
\hline significance & $\mathrm{p}<0.05$ & n.s. & n.s. & $\mathrm{p}<0.05$ \\
\hline odds ratio & 5.0 & - & - & 3.3 \\
\hline
\end{tabular}

CM - clinical mastitis; RPD - reproductive and periparturient disorders; ATB - administration of antibiotics

* amoxicillin/clavulanic acid, cephapirin, neomycin/oxytetracycline and cephalexin were used for treatment of clinical mastitis, metritis, retained placenta and dry-off, respectively; **Streptococcus uberis, Streptococcus dysgalactiae and Streptococcus agalactiae; n.s. non significant 


\section{Biofilm formation and PFGE}

All isolates of $S$. aureus were capable of biofilm formation and were positive for the ica operon (i.e., the icaAB genes). None of the isolates was positive for the bap gene. All $S$. aureus isolates had the same PFGE profile.

\section{Discussion}

The aim of this study was to describe the epidemiology of $S$. aureus and mastitis streptococci in a dairy cattle herd with anamnesis of recurrent clinical mastitis and decreased milk production. We have found that identification of cows subclinically infected with $S$. aureus was more reliable when the animals were sampled more than once (Table 1). Thus, in the screening of dairy herds for $S$. aureus it is important that cows are systematically monitored for this pathogen. The repeated finding of $S$. aureus in the same cows also indicates that infections of the udder with this pathogen may be persistent.

One of the factors promoting the occurrence of persistent infections is the ability of pathogens to form biofilms and to thereby increase their tolerance to antimicrobial agents (Melchior et al. 2006). In the present study, despite in vitro susceptibility of $S$. aureus to potentiated penicillins (ampicillin/sulbactam) and cephalosporins, no decrease in the occurrence of $S$. aureus was observed in cows undergoing intramammary treatment with amoxicillin/clavulanic acid (a potentiated penicillin antibiotic). This could be explained by the fact that all $S$. aureus isolates were capable of biofilm formation and were positive for the $i c a$ operon (i.e., the $i c a A B$ genes). Such intramammary persistence of $S$. aureus due to biofilm formation could also be potentiated by the fact that all the isolates were resistant to ampicillin and produced $\beta$-lactamases, which may increase their tolerance to the antibiotics that were administrated via the intramammary route (i.e., to amoxicillin/clavulanic acid and cephalosporins).

In our previous work, we observed that a high prevalence of $S$. aureus was typical only for a few dairy farms and we suggested that certain genetic subpopulations of $S$. aureus may be present (Cervinkova et. 2013). In contrast, in the present study, all isolates of $S$. aureus belonged to the same PFGE type. This strongly suggests that clonal spread of this pathogen may occur within a single herd. Although the clonal spread of $S$. aureus mastitis strains has also been observed by other authors (Castelani et al. 2013), an exclusive persistence and spread of only one clone within a single herd is, to our knowledge, a novel finding. Because $S$. aureus is regarded as a typical contagious pathogen, this finding further underlines the necessity of implementing proper milking hygiene in order to restrict its spread among individual animals (only a pre-milking teat dip without washing of soiled udder and proper hand hygiene of milkers was implemented during the milking).

There are several contradictory reports on the occurrence of $S$. aureus and mastitis streptococci in milk with regard to the parity. In our study, cows that were in a higher parity were shown to be more frequently positive for $S$. aureus $(\mathrm{p}<0.01$; Chi-squared test for trend; Table 2). This implies that the risk of $S$. aureus mastitis may increase with the increasing number of parity. However, this phenomenon was not observed with regard to mastitis streptococci ( $>0.05$, Chi-squared test for trend; Table 2). A higher prevalence of $S$. aureus and mastitis streptococci in cows of higher parity was described in several studies (Tenhagen et al. 2006, Ramirez et al. 2014). On the other hand, no association between the parity and occurrence of $S$. aureus and streptococci in milk was observed by Goli et al. (2012). Osteras et al. (2006) described the influence of the parity on the prevalence of $S$. dysgalactiae but not $S$. aureus. With these reports in mind, it can be concluded that the parity may represent a risk factor for mastitis, but its role in the occurrence of the disease should be interpreted on a herd-level basis.

It is well known that SCC is a useful predictor of IMI (Sharma et al. 2011). In our study, statistically significant increase in prevalence of $S$. aureus and mastitis streptococci was associated with the higher SCC numbers $(>150000 ; p<0.05$ at least; Fisher's exact test; Table 3). But this relationship was not confirmed for other potential mastitis pathogens (Table 3). According to some authors (Ferreira et al. 2012), occurrence of $S$. aureus and mastitis streptococci in milk may contribute to total bacterial counts in raw milk. This was also confirmed in this study, when statistically significant increase in prevalence of $S$. aureus, mastitis streptococci, other streptococci and EFS was correlated with higher TBC numbers ( $>100000 ; p<0.05$; Fisher's exact test; Table 3 ), except other enterococci ( $p>0.05$ Fisher's exact test; Table 3).

Zadoks et al. (2001) found that previous cases of clinical mastitis caused by $S$. aureus and $S$. uberis led to higher rates of subsequent IMI with these pathogens. In the present study, we observed that the occurrence of mastitis streptococci (mainly S. uberis) in milk was linked with previous cases of clinical mastitis $(\mathrm{p}<0.05$; Fisher's exact test; $\mathrm{OR}=5.0)$ but this dependence was not confirmed for $S$. aureus (Table 4). 
Some authors also described a certain level of correlation between mastitis and RPD, i.e. ovarian dysfunctions, metritis, retained placenta and milk fever (Heringstad et al. 2005, Nguyen et al. 2011, Rahman et al. 2012). Suriyasathaporn et al. (2000) reported that retained placenta and milk fever increase the risk for clinical mastitis caused by different pathogens including $S$. aureus and mastitis streptococci. However, no association between RPD and the occurrence of main mastitis pathogens in milk was observed in the present study (Table 4).

The influence of the administration of antibiotics via either the systemic or intramammary route on the occurrence of IMI was studied by several authors. While some authors reported a very low or nonexistent effect of intramuscular antibiotic administration on the prevalence of staphylococci and streptococci in milk (Shpigel et al. 2006, Contreras et al. 2013), other authors observed a decrease in the occurrence of these pathogens in milk after treatment with antibiotics by the same route (Sandgren et al. 2008, Ataee et al. 2009). In the present study, however, no dependence between antibiotic administration and occurrence of the monitored pathogens in milk was observed with one exception. A positive relationship $(p<0.05$; Fisher's exact test) was observed between intramammary administration of antibiotics and occurrence of mastitis streptococci in milk. This may be explained by the fact that all cases of clinical mastitis were treated intramammarily with amoxicillin/ clavulanic acid (a potentiated penicillin antibiotic) and all isolates of mastitis streptococci were resistant to ampicillin/sulbactam (an equivalent to amoxicillin/clavulanic acid). This was also in accordance with the abovementioned positive relationship between previous cases of clinical mastitis and the occurrence of mastitis streptococci in milk. It has been reported that intramammary application of penicillin may lead to positive selection for penicillin-resistant strains in the udder (Osteras et al. 1999).

In conclusion, although the occurrence of recurrent clinical mastitis is likely to be related to resistant mastitis streptococci rather than to $S$. aureus, the latter pathogen, due to its high prevalence, seems to be the major cause of subclinical mastitis in this case (as demonstrated via increased SCC values of milk). A positive relationship between TBC and $S$. aureus in milk as well as the clonal spread of this pathogen within the herd is indicative of an inappropriate level of hygiene during the milking process. Due to its ability to form biofilm, $S$. aureus can persist in the udder for a long time, with increasing risk for new infections with rising parity.

\section{Acknowledgments}

This work was financially supported by the Ministry of Agriculture of the Czech Republic - NAZV (QJ1210301) and (RO0516), and by the Ministry of Education, Youth and Sports of the Czech Republic - NPU I (LO1218). Neysan Donnelly (Max Planck Institute of Biochemistry, Munich, Germany) is thanked for the grammatical correction of the manuscript.

\section{References}

Ataee O, Hovareshti P, Bolourchi M, Barin A, Gerami A, Niasari-Naslaji A (2009) Effect of systemic antibacterial administration during prepartum period on coagulase negative staphylococcal intramammary infection in holstein heifers. Iran J Vet Res 10: 255-259.

Awale MM, Dudhatra GB, Avinash K, Chauhan BN, Kamani DR, Modi CM, Patel HB, Mody SK (2012) Bovine mastitis: a threat to economy. Open Access Scientific Reports 1: 295. doi:10.4172/scientificreports.295.

Castelani L, Santos AF, Dos Santos Miranda M, Zafalon LF, Pozzi CR, Arcaro JR (2013) Molecular typing of mastitis-causing Staphylococcus aureus isolated from heifers and cows. Int J Mol Sci 14: 4326-4333.

Cervinkova D, Vlkova H, Borodacova I, Makovcova J, Babak V, Lorencova A, Vrtkova I, Marosevic D, Jaglic $\mathrm{Z}$ (2013) Prevalence of mastitis pathogens in milk from clinically healthy cows. Veterinarni medicina 58: 567-575.

Contreras GA, Munoz JD, Sears PM (2013) Reducing the incidence of intramammary infection in heifers by using prepartum systemic tylosin therapy: initial results of a single herd pilot study. Rev colomb cienc pec 26: 119-126.

Ferreira Lopes Junior JE, Lange CC, Vasconcelos Paiva Brito MA, Santos FR, Souto Silva MA, Dutra de Moraes LC, de Souza GN (2012) Relationship between total bacteria counts and somatic cell counts from mammary quarters infected by mastitis pathogens. Cienc Rural 42: 691-696.

Goli M, Ezzatpanah H, Ghavami M, Chamani M, Aminafshar M, Toghiani M, Eghbalsaied S (2012) The effect of multiplex-PCR-assessed major pathogens causing subclinical mastitis on somatic cell profiles. Trop Anim Health Prod 44: 1673-1680.

Heringstad B, Chang YM, Gianola D, Klemetsdal G (2005) Genetic analysis of clinical mastitis, milk fever, ketosis, and retained placenta in three lactations of Norwegian red cows. J Dairy Sci 88: 3273-3281.

Jaglic Z, Michu E, Holasova M, Vlkova H, Babak V, Kolar M, Bardon J, Schlegelova J (2010) Epidemiology and characterization of Staphylococcus epidermidis isolates from humans, raw bovine milk and a dairy plant. Epidemiol Infect 138: 772-782.

Kadariya J, Smith TC, Thapaliya D (2014) Staphylococcus aureus and staphylococcal food - borne disease: an ongoing challege in public health. Biomed Res Int 2014: 827965.

Kvapilik J (2015) Incidence of mastitis in dairy herds. Nas chov 8: 42-46. 
Martineau F, Picard FJ, Roy PH, Ouellete M, Bergeron MG (1998) Species-specific and ubiquitous-DNA-based assays for rapid identification of Staphylococcus aureus. J Clin Microbiol 36: 618-623.

Melchior MB, Vaarkamp H, Fink-Gremmels J (2006) Biofilms: a role in recurrent mastitis infections? Vet $\mathbf{J}$ 171: 398-407.

Nguyen TC, Nakao T, Gautam G, Su LT, Ranasinghe RM, Yusuf M (2011) Relationship between milk somatic cell count and postpartum ovarian cyclicity and fertility in dairy cows. Acta Vet Hung 59: 349-362.

Osteras O, Martin SW, Edge VL (1999) Possible risk factors associated with penicillin-resistant strains of Staphylococcus aureus from bovine subclinical mastitis in early lactation. J Dairy Sci 82: 927-938.

Osteras O, Solverod L, Reksen O (2006) Milk culture results in a large Norwegian survey - effects of season, parity, days in milk, resistance, and clustering. J Dairy Sci 89: 1010-1023.

Rahman MM, Mazzilli M, Pennarossa G, Brevini TA, Zecconi A, Gandolfi F (2012) Chronic mastitis is associated with altered ovarian follicle development in dairy cattle. J Dairy Sci 95: 1885-1893.

Ramirez NF, Keefe G, Dohoo I, Sanchez J, Arroyave O, Ceron J, Jaramillo M, Palacio LG (2014) Herd- and cow-level risk factors associated with subclinical mastitis in dairy farms from the high plains of the northern Antioquia, Colombia. J Dairy Sci 97: 4141-4150.

Sandgren CH, Waller KP, Emanuelson U (2008) Therapeutic effects of systemic or intramammary antimicrobial treatment of bovine subclinical mastitis during lactation. Vet J 175: 108-117.

Seegers H, Fourichon C, Beaudeau F (2003) Production effects related to mastitis and mastitis economics in dairy cattle herds. Vet Res 34: 475-491.

Sharma N, Singh NK, Bhadwal MS (2011) Relationship of somatic cell count and mastitis: an overview. Asian-Australas J Anim Sci 24: 429-438.

Shpigel NY, Kass PH, Saran A (2006) A comparative randomized field trial on intramammary and intramuscular dry cow antibiotic treatment of subclinical Staphylococcus aureus mastitis in dairy cows. J Vet Med A 53: 418-422.

Stepanovic A, Vukovic D, Hola V, di Bonaventura G, Djukic S, Cirkovic I, Ruzicka F (2007) Quantification of biofilm in microtiter plates: overview of testing conditions and practical recommendations for assessment of biofilm production by staphylococci. APMIS 115: 891-899.

Suriyasathaporn W, Schukken YH, Nielen M, Brand A (2000) Low somatic cell count: a risk factor for subsequent clinical mastitis in a dairy herd. J Dairy Sci 83: $1248-1255$.

Tenhagen BA, Koster G, Wallmann J, Heuwieser W (2006) Prevalence of mastitis pathogens and their resistance against antimicrobial agents in dairy cows in Brandenburg, Germany. J Dairy Sci 89: 2542-2551.

Zadoks RN, Allore HG, Barkema HW, Sampimon OC, Wellenberg GJ, Grohn YT, Schukkent YH (2001) Cow- and quarter-level risk factors for Streptococcus uberis and Staphylococcus aureus mastitis. J Dairy Sci 84: 2649-2663. 